\title{
Bond and topography evaluation of a Y-TZP ceramic with a superficial low-fusing porcelain glass layer after different hydrofluoric acid etching protocols
}

\author{
Avaliação da adesão e topografia de uma zircônia Y-TZP com uma camada de glaze após diferentes \\ protocolos de condicionamento com ácido fluorídrico
}

\author{
Arthur Chaves SIMÕES ${ }^{a}$, Jean Soares MIRANDA ${ }^{\text {b* }}$, Rodrigo Othávio de Assunção e SOUZA', \\ Estevão Tomomitsu KIMPARA ${ }^{\text {b }}$, Fabíola Pessôa Pereira LEITEa
}

aUFJF - Universidade Federal de Juiz de Fora, Juiz de Fora, MG, Brasil

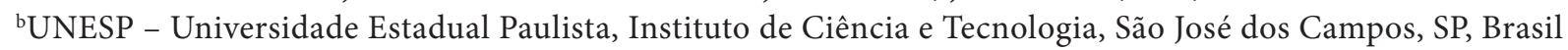
'UFRN - Universidade Federal do Rio Grande do Norte, Natal, RN, Brasil

\begin{abstract}
Resumo
Introdução: Apesar de ser uma das cerâmicas mais estudadas atualmente, a zircônia ainda não possui um protocolo bem definido para uma cimentação adesiva. Objetivo: Avaliar a influência de diferentes tempos de condicionamento e concentrações do ácido fluorídrico (AF) na superfície da zirconia e na resistência de união entre uma cerâmica Y-TZP vitrificada e um cimento resinoso. Material e método: Os tratamentos de superfície foram: jateamento com óxido de alumínio revestido com sílica (Co); aplicação de glaze + condicionamento com AF 5\% por 5s (G5-5s), 10s (G5-10s) ou 20s (G5-20s); aplicação de glaze + condicionamento com AF 10\% por 5s (G10-5s), 10 (G10-10s) ou 20s (G10-20s). Em seguida, cilindros de cimento $(3,3 \times 3,3 \mathrm{~mm})$ para teste de cisalhamento foram feitos em todos os espécimes. Os espécimes foram submetidos a 6000 ciclos térmicos antes do teste de adesão. As fraturas foram analisadas por estereomicroscópio. Os dados foram analisados estatisticamente por Kruskal-Wallis e Dunn (5\%). Amostras extra de cada grupo foram feitas para realização de perfilometria e microscopia eletrônica de varredura (MEV). Resultado: A resistência de união zircônia-cimento foi afetada pelos tratamentos de superfície $(\mathrm{p}=0,001)$. Os grupos G10-5s (2,71 MPa) registraram os maiores valores de resistência de união, seguidos pelos Co (2,05 MPa), enquanto os grupos G5 apresentaram o menor valor de união. Falhas adesivas foram predominantes. As análises por imagem revelaram que os grupos G5 parecem ser menos rugosos quando comparados aos grupos tratados com AF $10 \%$. A criação de poros na superfície vítrea (glaze) ocorreu apenas quando foi utilizado AF 10\%. Conclusão: A aplicação de camada de vidro de porcelana de baixa fusão foi capaz de superar o jateamento e obter uma maior adesão adesiva ao cimento resinoso, no entanto, somente quando foi utilizado $10 \%$ de HF por um intervalo de 5 segundos.
\end{abstract}

Descritores: Zirconia; glaze; adesão; tratamento de superfície.

\begin{abstract}
Introduction: Despite being one of the most studied ceramics today, zirconia still does not have a well-defined adhesion protocol. Objective: Evaluate the influence of different etching times and hydrofluoric acid (HF) concentrations on the zirconia surface and bond strength between a vitrified Y-TZP ceramic and a resin cement. Materials and method: The zirconia surface treatments were: sandblasting with silica-coated alumina (Co); glaze application $+5 \% \mathrm{HF}$ etching for $5 \mathrm{~s}$ (G5-5s), $10 \mathrm{~s}$ (G5-10s) or 20s (G5-20s); glaze application + 10\% HF etching for 5s (G10-5s), 10 (G10-10s) or 20s (G10-20s) . Then, cement cylinders $(3.3 \times 3.3 \mathrm{~mm})$ were built up for shear bond test on all specimens. The specimens were subjected to 6000 thermal cycling before the test. Fractures were analyzed by stereomicroscope. Data were statistically analyzed by Kruskal-Wallis and Dunn statistical tests (5\%). Extra samples of each group were made to obtain profilometry and scanning electron microscopy (SEM). Result: Zirconia-cement bond strength was affected by the ceramic surface treatments $(\mathrm{p}=0.001)$. G10-5s $(2.71 \mathrm{MPa})$ recorded the highest bond strength values, followed by the Co (2.05 MPa) while G5 groups had the lowest bond value. Adhesive failure of the samples predominated. The image analysis revealed G5 groups seem to have a lower roughness when compared to groups treated by $10 \% \mathrm{HF}$. The creation of pores in the low-fusing porcelain glass layer surface occurred only when $10 \% \mathrm{HF}$ was used. Conclusion: The low-fusing porcelain glass layer application was able to overcome the sandblasting and obtain a greater adhesive bond to the resinous cement, however, only when $10 \% \mathrm{HF}$ was used for an interval of 5 seconds.
\end{abstract}

Descriptors: Zirconia; glaze; adhesion; surface treatment. 


\section{INTRODUCTION}

Among dental ceramics, zirconia has the greatest fracture toughness and flexural strength ${ }^{1}$. In addition, this material has the "transformation toughening" mechanism, in which its grains turn from a tetragonal to monoclinic phase, with volumetric expansion, to prevent crack propagation ${ }^{2}$.

However, the adhesion between this dental ceramic and the tooth, one of the decisive factors for achieving longevity of the restoration $^{3-5}$ it is not established and it is a critical factor ${ }^{6}$ because the hydrofluoric acid (HF) have almost no effects on zirconia due to the fact that this material is highly crystalline, without a vitreous content $^{4,7-12}$.

Therefore, it was necessary to develop some different surface treatments options to zirconia, trying to promote micro retentions and/or make the surface chemically reactive to an adhesive system ${ }^{12}$. These surface treatment options were sandblasting with aluminum oxide particles ${ }^{13}$, laser irradiation ${ }^{14}$, sandblasting with aluminum oxide coated by silica particles ${ }^{3,15}$, the use of metal primers ${ }^{10,13,14}$, plasma selective infiltration ${ }^{15}$ and a low-fusing porcelain glass layer application ${ }^{16-19}$ was tried.

This last surface treatment referred as vitrification aims to enrich the surface with silicon oxides and allow hydrofluoric acid (HF) etch to selectively attack this glass layer and change its topography, providing areas for mechanical retention. In addition, this etching would increase the ceramic surface energy and its adhesive potential, a necessary condition to obtain a stable and durable bonding of the resin cement to the substrate $e^{5,7,13,20}$. The silane is also applied to ensure a chemical bond, similar to what happens in the glass- ceramic adhesion process ${ }^{12,20}$.

However, the numbers of layers, the ideal HF concentration and etching time on this surface is not yet defined. Thus, this research aimed to evaluate the influence of different etching times and some hydrofluoric acid concentrations on the etching process and bond strength between a vitrified Y-TZP ceramic and a resin cement. The null hypotheses were: (1) the low-fusing porcelain glaze application would not influence the bond strength to the Y-TZP ceramic, (2) the HF concentration and (3) the etching time of the experimental groups would not alter this result.

\section{MATERIAL AND METHOD}

\section{Specimen Preparation}

Some Y-TZP zirconia blocks (IPS e.max ZirCAD - Ivoclar-Vivadent, Schaan, Liechtenstein) were sectioned in a cutting machine diamond wheel (Isomet 1000, Buehler, Lake Bluff, IL, USA) into a square specimens, which were polished with \#180, 400, 600 and 1200 grit silicon carbide papers under water cooling. After this, they were cleaned in distilled water for $5 \mathrm{~min}$ in an ultrasonic bath $^{18}$. Then, the specimens were sintered in a furnace (Zyrcomat T, Vita Zahnfabrik, Bad Sackingen, Germany) according to the pre-defined manufacturer's directions. The final dimensions of the blocks were $12 \times 12 \times 1.5 \mathrm{~mm}^{16}$.

\section{Surface Treatment}

The sintered blocks were randomly assigned to seven groups $(\mathrm{n}=10)$ according to surface treatment, as follows:

Co (control): The sandblasting with silica-coated alumina was performed by Rocatec Soft (3M ESPE, St. Paul, Minnesota, USA) at a distance of $10 \mathrm{~mm}$ between the zirconia surface and the apparatus tip (Dento-PrepTM, RØNVIG A / S) with a $45^{\circ}$ slope, at 2.8 bars of pressure for $15 \mathrm{~s}$.

G5-5s: glaze spray (VITA AKZENT Plus, Vita Zahnfabrik, German) was applied twice and sintered according to the manufacturer's guidelines. Subsequently, the glazed surface was etched with 5\% hydrofluoric acid gel (HF) (5\% Condac Porcelana FGM, Pinheiros, SP, Brazil) for 5 seconds, rinsed with air-water spray, and dried. Finally, the samples were cleaned in a sonic bath (five minutes in distilled $\mathrm{H} 2 \mathrm{O}$ ).

G5-10s: glaze spray was applied twice, sintered, etched with 5\% HF for 10 seconds, rinsed with air-water spray, dried and cleaned in a sonic bath (five minutes in distilled $\mathrm{H} 2 \mathrm{O}$ ).

G5-20s: glaze spray was applied twice, sintered, etched with 5\% HF for 20 seconds, rinsed with air-water spray, dried and cleaned in a sonic bath (five minutes in distilled $\mathrm{H} 2 \mathrm{O}$ ).

G10-5s: glaze spray was applied twice, sintered, etched with $10 \%$ HF for 5 seconds, rinsed with air-water spray, dried and cleaned in a sonic bath (five minutes in distilled $\mathrm{H} 2 \mathrm{O}$ ).

G10-10s: glaze spray was applied twice, sintered, etched with $10 \%$ HF for 10 seconds, rinsed with air-water spray, dried and cleaned in a sonic bath (five minutes in distilled $\mathrm{H} 2 \mathrm{O}$ ).

G10-20s: glaze spray was applied twice, sintered, etched with $10 \% \mathrm{HF}$ for 20 seconds, rinsed with air-water spray, dried and cleaned in a sonic bath (five minutes in distilled $\mathrm{H} 2 \mathrm{O}$ ).

After conditioning the Y-TZP bonding surface, all blocks were fixed in a cylinder fulfilled by acrylic resin with the adhesive interface perpendicular to the horizontal plane. All of the specimens were submitted to silanization for five minutes (RelyX Ceramic Primer).

A pilot was performed by applying only once the glaze spray in each sample. However, when this was done all samples failed prematurely to the shear bond test. For this reason, the double application of the same was done.

\section{Cement Application}

A cement was mixed (RelyX ARC, 3M ESPE, St. Paul, Minnesota, USA) and applied using a syringe (Centrix Syringe system, Dentsply Detrey, Konstanz, Germany) inside two silicon matrix $(3 \mathrm{~mm}$ internal diameter by $2 \mathrm{~mm}$ ) by block that had been placed on the ceramic surface, totaling twenty adhesive interfaces per group to be tested. The resin cement was light-cured for 40 seconds (Valo, Ultradent, South Jordan, USA). After luting, all samples were stored in distilled water (Olidef, Ribeirão Preto, São Paulo, Brazil) at $37^{\circ} \mathrm{C}$ for 24 hours. Next, the silicon matrices were removed with blades (Becton Dickinson, New Jersey, USA), obtaining the final specimens for the research ${ }^{18}$. 


\section{Aging Procedure}

After the luting process, all the specimens were subjected to thermal cycling aging for 6.000 cycles (Nova Ética, São Paulo, SP, Brazil $)$ at $55^{\circ} \mathrm{C}\left( \pm 2^{\circ}\right)$ and $5^{\circ}\left( \pm 2{ }^{\circ} \mathrm{C}\right)$ with 30 s immersion baths and transfer bath time was $2 \mathrm{~s}^{18}$.

\section{Shear Bond Strength Test}

Shear bond tests were performed in a universal testing machine (EMIC DL 1000, Sao Jose dos Pinhais, PR, Brazil). A 10 kgf load was applied to the adhesive interface at a constant crosshead speed of $1.0 \mathrm{~mm} / \mathrm{min}$. The specimens were subjected to shear stress by steel wire orthodontic $(\phi=0.5 \mathrm{~mm})$ until debonding ${ }^{18}$ (Figure 1).

\section{Failure Analysis}

The fractured surfaces were analyzed by stereomicroscope (Discovery V20; Carl-Zeiss, Gottingen, Germany) at 20x magnification. The failures were classified as adhesive, cohesive or mixed failure.

\section{Surface Characterization}

One of the extra samples was also examined in a digital optical profilometer (Wyko, Modelo NT 1100, Veeco, Tucson, USA) connected to a computer with image software (Vision 32, Veeco, Tucson, USA) to perform surface micrographs (qualitative analysis of three-dimensional geometry).

The same samples were then cleaned with $70 \%$ alcohol (Alves Santa Cruz Ltda. - Guarulhos, São Paulo, Brazil), dried and metallized (EMITECH SC7620), receiving a thin layer (12nm) of gold alloy. They were examined using a scanning electron microscope (SEM; INSPECT S50, FEI, Czech Republic) to obtain mapping, backscattered electron detector (BSE) and conventional SEM images.

\section{Statistical Analysis}

To evaluate the surface treatment influence on bond strength, the data were submitted to Kruskal-Wallis and Dunn statistical tests. The significance level for all tests was $95 \%$.
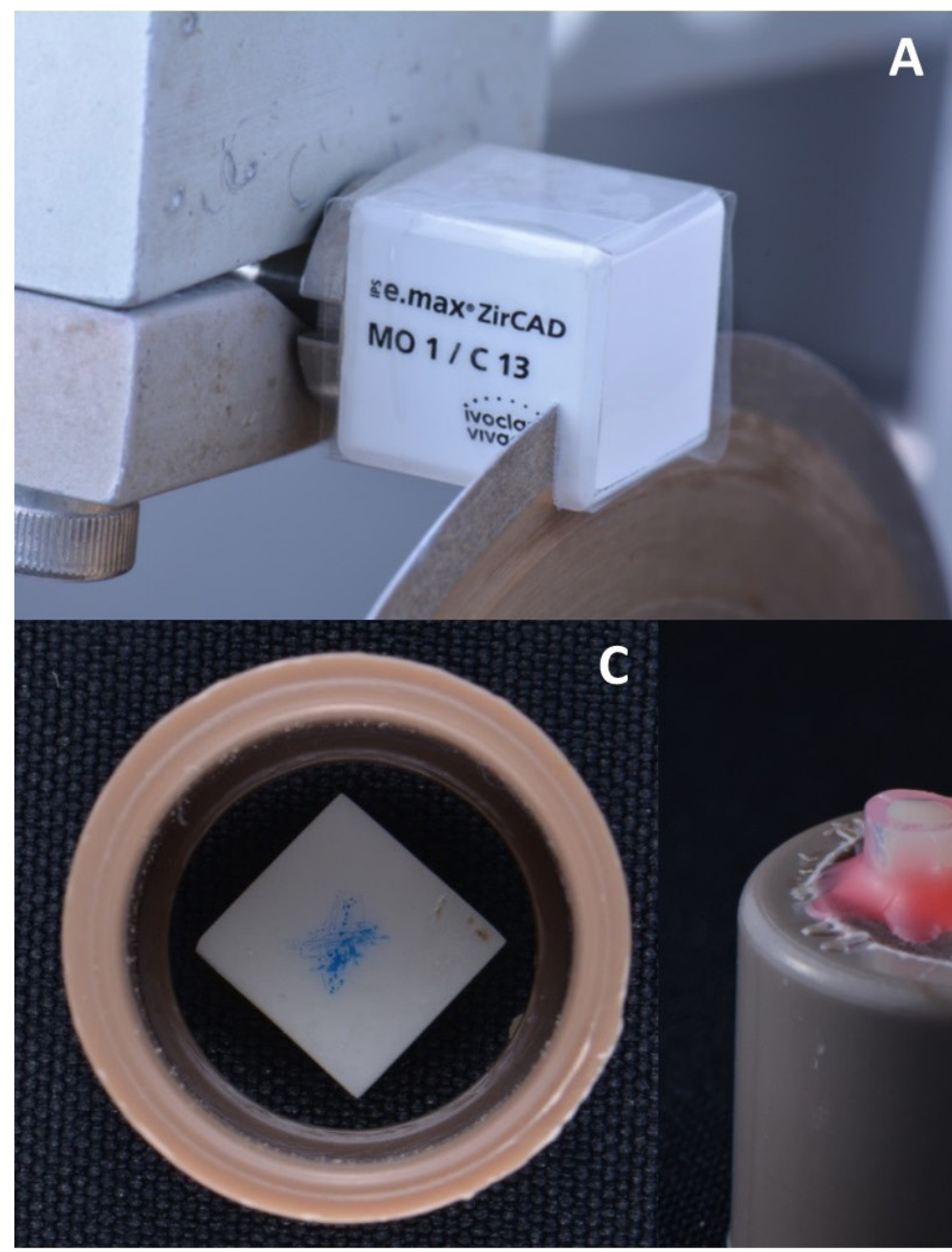

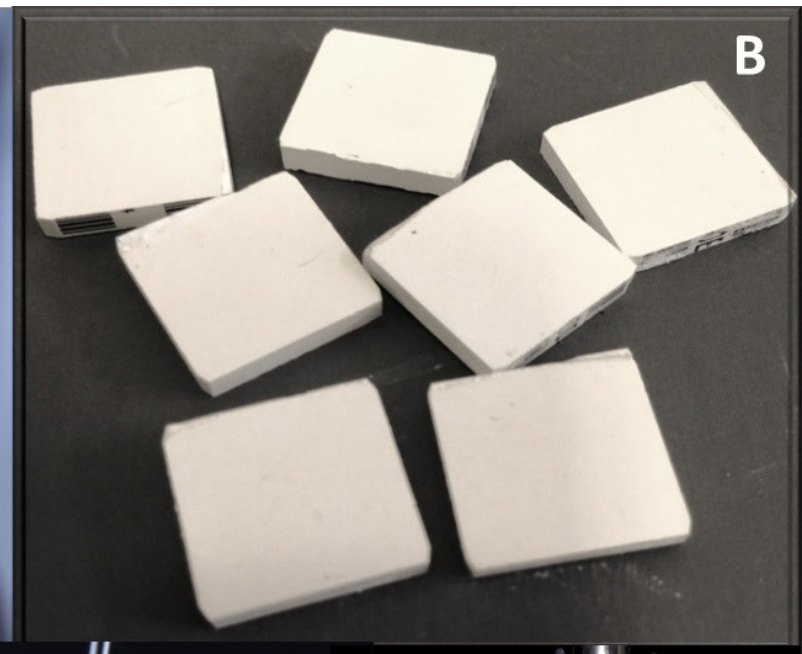

D

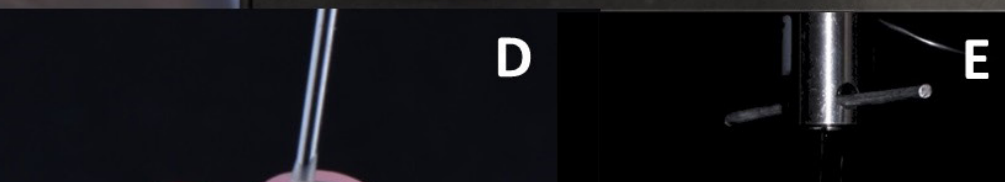

Figure 1. For the samples preparation, the pre-sintered YTZ-P zirconia blocks were sliced with a thickness of $2 \mathrm{~mm}$ (A). These slices were polished and sintered (B). After the surface treatments, they were individually included in acrylic resin $(\mathrm{C})$. After the resin cure, the cementation process started (D), for the subsequent execution of the shear bond test (E). 


\section{RESULT}

\section{Shear Bond Strength Test and Failure Mode}

The Kruskal-Wallis test revealed a significant interaction of the surface treatment $(\mathrm{p}=0.001)$. Using Dunn's test $(\mathrm{p} \leq 0.05)$, it was possible to verify that bond strength mean values of the G10-5s group were statistically higher, followed by Ro and G10-20s. G10-10s and G5 groups had the lower bond strength results. Pre-test failures occurred in all groups, reducing the " $n$ " of each of them (Table 1). They were characterized by cement detachment during thermocycling. Stereomicroscopic analysis revealed complete adhesive failures (100\%) (Figure 2).

\section{Surface Analysis}

The profilometry analysis showed that the groups etched by $5 \%$ HF seem to have a lower roughness when compared to groups treated by $10 \% \mathrm{HF}$. In the SEM images, it can be noticed that the creation of pores in the low-fusing porcelain glass layer surface occurred only when $10 \% \mathrm{HF}$ was used.

Table 1. Dunn test results for bond strength values (MPa)

\begin{tabular}{cccc}
\hline & n & Mean \pm Std Deviation & \\
\hline Co & 16 & $2.05 \pm 0.82$ & B \\
G5-5s & 8 & $0.26 \pm 0.07$ & CD \\
G5-10s & 9 & $0.11 \pm 0.08$ & D \\
G5-20s & 6 & $0.18 \pm 0.13$ & D \\
G10-5s & 8 & $2.71 \pm 0.61$ & A \\
\hline G10-10s & 7 & $0.54 \pm 0.08$ & $\mathrm{C}$ \\
\hline G10-20s & 16 & $2.03 \pm 0.88$ & B \\
\hline
\end{tabular}

Different letters indicate a significant difference between groups.

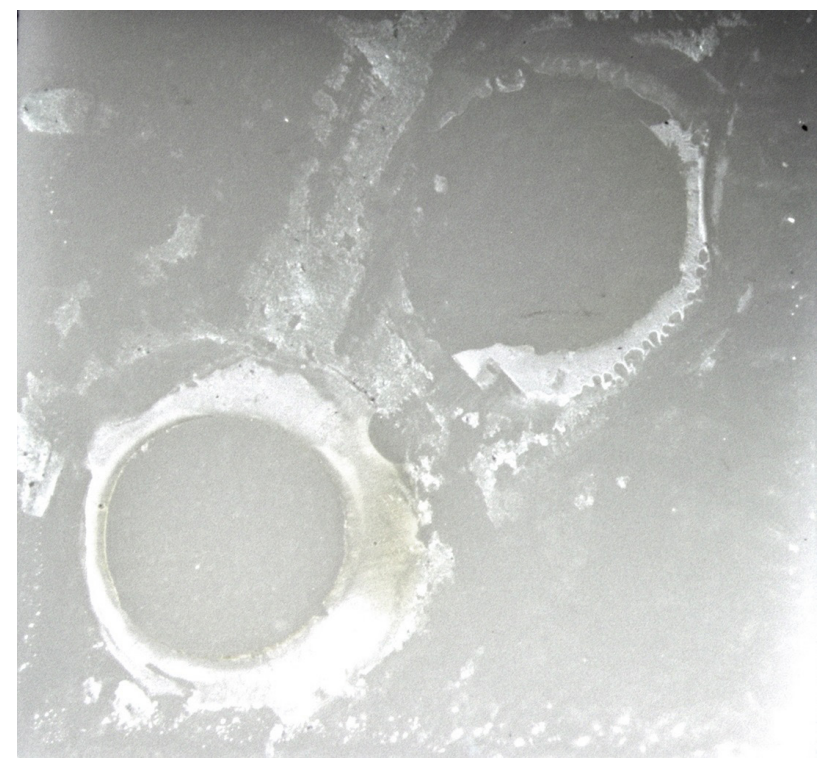

Figure 2. Microscopy in a stereomicroscopy (20x magnification) after the shear test indicating the adhesives failure, in which the cement was released from YTZ-P ceramic.

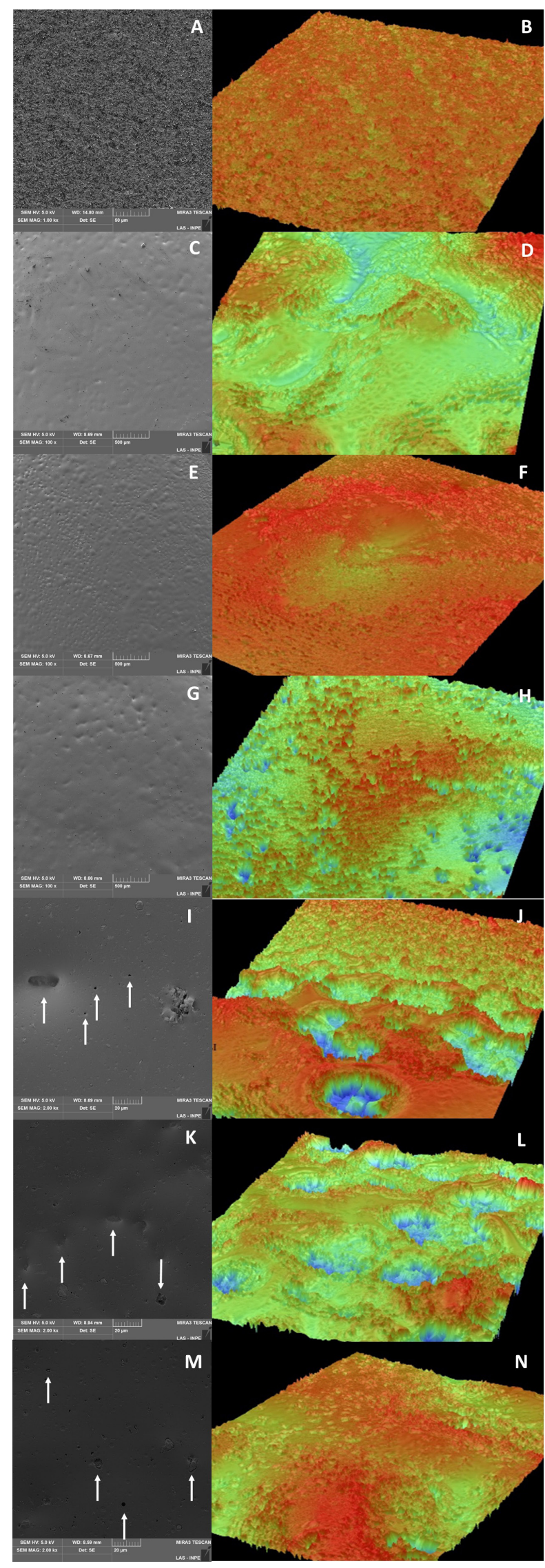

Figure 3. Micrographs (1000x) and 3D images of the surface roughness after the surface treatments. (A, B) Control group; (C, D) G5-5s; (E, F) G5-10s; (G, H) G5-20s; (I, J) G10-5s; (K, L) G10-10s; (M, N) G10-20s. The groups with the low-fusing porcelain glass layer etched with $10 \% \mathrm{HF}$ have a rougher surface in the $3 \mathrm{D}$ images and the scanning microscopes show the creation of pores (pointed by the arrows) that can help in the micromechanical retention of the ceramic to the resin cement. 


\section{DISCUSSION}

As mentioned, the goal of this study was to evaluate the influence of different the etching times and the hydrofluoric acid concentrations on the etching process and bond strength between a vitrified Y-TZP ceramic and a dental resin agent, without MDP (10-methacryloyloxydecyl dihydrogen phosphate). In this research, the application of the double low-fusing porcelain glass layer followed by the $10 \% \mathrm{HF}$ etching was more effective for bond strength than the control group, which leads to the negation of the first null hypothesis.

This fact can be a good thing, because despite airborne particle abrasion for densely sintered all-ceramic restorations improve micromechanical retention by means of surface roughening (Figure 3$)^{21}$, such processes can create cracks on restoration surface and decrease its strength to some extent ${ }^{13}$. Although only G10-5s presented better results than control, the thin glass layer applied to the zirconia surface presents as an advantageous and non-destructive treatment that enriches the surface with silicon oxides, which facilitates chemical bonding by the silane application ${ }^{5,13}$. In addition, the vitrification allows HF etching of the glass layer, which modifies the surface topography and creates micromechanical retentions ${ }^{7,13,21}$. This surface treatment was proof efficient even by fatigue survival tests ${ }^{19}$

The data also showed that the 5\% HF etching of the low-fusing porcelain glass layer generated almost null bond strength, lower than the control group and those conditioned with $10 \% \mathrm{HF}$, except for G10-10s, which presented values similar to G5-5s, leading to the partial negation of the second null hypothesis. This may have happened because of the lower surface roughness observed when the conditioning is performed with 5\% HF (Figure 3), which resulted in a lower micromechanical retention. According to some authors ${ }^{1,12}$, the micromechanical retention is more favorable for adhesion of the luting material to the Y-TZP than the chemical bond that is created due to the increase of silica on the treated surface.

This low concentration of HF did not even allow conditioning time to influence surface properties, unlike when $10 \% \mathrm{HF}$ was used. In the G10 groups, it was noticed that a shorter conditioning time $(5 \mathrm{~s})$ produced a better resistance to adhesion, which leads us to partial acceptance of the third null hypothesis. Differently from that of Wandscher et al..$^{22}$, however, these studies can not be compared due to the different design of the specimens and the use of different luting agents.

Failure analysis indicated that these were always adhesive (Figure 2), independently of the groups, and the zirconia blocks were adhesive and cement free. This has also been observed in other studies ${ }^{3,10,23}$. These failures may be associated with several factors: thermal expansion difference between the materials ${ }^{23,24}$, processing techniques, phase transformation and factors related to the adhesive system ${ }^{24}$. The adhesive system used in this research does not have MDP, which is a monomer designed to bond to metal oxides such as zirconium. This may explain our low bond results, which, despite being close to that found by Wandscher et al. ${ }^{22}$, are lower than the ones that used MDP adhesive systems ${ }^{1,12,23}$.

Another factor that may be responsible for the low values of bond strength found is thermocycling. In this research, the number of 6000 thermal cycles was adopted, a quantity also used by other researchers ${ }^{13}$, who had also reported reduced union strength or premature failure due to thermocycling. The combination of hydrolytic degradation, diffusion of water into the interfacial layer and thermal irradiation during thermal cycles favors this degradation ${ }^{13}$. With this, it is observed that zirconia and its adhesive interface are sensible to aging. According to Ntala et al. ${ }^{5}$, even cemented parts with adhesive systems that have MDP have their adhesion reduced after thermocycling, but the presence of this phosphate monomer would generate conditions capable of better supporting this aging.

From the analysis performed, the application of double low-fusing porcelain glass layer followed by the $10 \% \mathrm{HF}$ etching seems to be a path to obtain adhesion to Y-TZP ceramics, with G10-5s being the group with best results. However, this laboratorial research has limitations and other protocols have yet to be evaluated, such as application of powder/liquid glaze by brush technique, in order to obtain better standardization of the glaze application, which does not seem to be guaranteed with the spray application.

\section{CONCLUSION}

The double low-fusing porcelain glass layer application was able to overcome the sandblasting and to obtain a greater adhesive bond to the resinous cement, however, only when $10 \% \mathrm{HF}$ was used for an interval of 5 seconds.

\section{REFERENCES}

1. Moradabadi A, Roudsari SE, Yekta BE, Rahbar N. Effects of surface treatment on bond strength between dental resin agent and zirconia ceramic. Mater Sci Eng C Mater Biol Appl. 2014 Jan;34:311-7. http://dx.doi.org/10.1016/j.msec.2013.09.015. PMid:24268263.

2. Mota YA, Cotes C, Carvalho RF, Machado JPB, Leite FPP, Souza ROA, et al. Monoclinic phase transformation and mechanical durability of zirconia ceramic after fatigue and autoclave aging. J Biomed Mater Res B Appl Biomater. 2017 Oct;105(7):1972-7. http://dx.doi.org/10.1002/ jbm.b.33720. PMid:27312806.

3. Cavalcanti AN, Foxton RM, Watson TF, Oliveira MT, Giannini M, Marchi GM. Y-TZP ceramics: key concepts for clinical application. Oper Dent. 2009 May-Jun;34(3):344-51. http://dx.doi.org/10.2341/08-79. PMid:19544825.

4. Attia A. Bond strength of three luting agents to zirconia ceramic: influence of surface treatment and thermocycling. J Appl Oral Sci. 2011 Aug;19(4):388-95. http://dx.doi.org/10.1590/S1678-77572011005000015. PMid:21710091. 
5. Ntala P, Chen X, Niggli J, Cattell M. Development and testing of multi-phase glazes for adhesive bonding to zirconia substrates. J Dent. 2010 Oct;38(10):773-81. http://dx.doi.org/10.1016/j.jdent.2010.06.008. PMid:20600558.

6. Feitosa SA, Patel D, Borges AL, Alshehri EZ, Bottino MA, Özcan M, et al. Effect of cleansing methods on saliva-contaminated zirconia: an evaluation of resin bond durability. Oper Dent. 2015 Mar-Apr;40(2):163-71. http://dx.doi.org/10.2341/13-323-L. PMid:25136900.

7. Martins ARM, Gotti VB, Shimano MM, Borges GA, Gonçalves LS. Improving adhesion between luting cement and zirconia-based ceramic with an alternative surface treatment. Braz Oral Res. 2015;29(1):54. http://dx.doi.org/10.1590/1807-3107BOR-2015.vol29.0054. PMid:25859635.

8. Arai M, Takagaki T, Takahashi A, Tagami J. The role of functional phosphoric acid ester monomers in the surface treatment of yttria-stabilized tetragonal zirconia polycrystals. Dent Mater J. 2017 Mar;36(2):190-4. http://dx.doi.org/10.4012/dmj.2016-060. PMid:28111385.

9. Moezzizadeh M, Nojedehian H, Valizadeh Haghi H. Effect of bioglass and silica coating of zirconia substrate on its bond strength to resin cement. Dent Mater J. 2017 Jan;36(1):54-62. http://dx.doi.org/10.4012/dmj.2015-382. PMid:27928098.

10. Özcan M, Yetkiner E. Could readily silanized silica particles substitute silica coating and silanization in conditioning zirconium dioxide for resin adhesion? J Adhes Sci Technol. 2016;30(2):186-93. http://dx.doi.org/10.1080/01694243.2015.1095628.

11. Vu VT, Oh GJ, Yun KD, Lim HP, Kim JW, Nguyen TPT, et al. Acid etching of glass-infiltrated zirconia and its biological response. J Adv Prosthodont. 2017 Apr;9(2):104-9. http://dx.doi.org/10.4047/jap.2017.9.2.104. PMid:28435619.

12. Vanderlei A, Bottino MA, Valandro LF. Evaluation of resin bond strength to yttria-stabilized tetragonal zirconia and framework marginal fit: comparison of different surface conditionings. Oper Dent. 2014 Jan-Feb;39(1):50-63. http://dx.doi.org/10.2341/12-269-L. PMid:23586656.

13. Amaral M, Belli R, Cesar PF, Valandro LF, Petschelt A, Lohbauer U. The potential of novel primers and universal adhesives to bond to zirconia. J Dent. 2014 Jan;42(1):90-8. http://dx.doi.org/10.1016/j.jdent.2013.11.004. PMid:24246687.

14. Dias de Souza GM, Thompson VP, Braga RR. Effect of metal primers on microtensile bond strength between zirconia and resin cements. J Prosthet Dent. 2011 May;105(5):296-303. http://dx.doi.org/10.1016/S0022-3913(11)60055-3. PMid:21530754.

15. Papia E, Zethraeus J, Ransbäck PÅ, Wennerberg A, Vult von Steyern P. Impaction-modified densely sintered yttria-stabilized tetragonal zirconium dioxide: methodology, surface structure, and bond strength. J Biomed Mater Res B Appl Biomater. 2012 Apr;100(3):677-84. http:// dx.doi.org/10.1002/jbm.b.31992. PMid:22278954.

16. Miranda JS, Malta NV, de Carvalho RLA, Souza ROA, Machado JPB, Leite FPP. Which low-fusing porcelain glaze treatment technique is better to promote a vitreous surface on Y-TZP ceramic? Rev Odonto Ciênc. 2018 Jul;32(4):174-9. http://dx.doi.org/10.15448/19806523.2017.4.28749.

17. Antunes MCF, Miranda JS, Carvalho RLA, Carvalho RF, Kimpara ET, Assunção e Souza RO, et al. Can low-fusing glass application affect the marginal misfit and bond strength of Y-TZP crowns? Braz Oral Res. 2018;32(0):e34. http://dx.doi.org/10.1590/1807-3107bor-2018. vol32.0034. PMid:29742232.

18. Yamamoto LT, Rodrigues VA, Dornelles LS, Bottino MA, Valandro LF, Melo RM. Low-fusing porcelain glaze application on 3y-tzp surfaces can enhance zirconia-porcelain adhesion. Braz Dent J. 2016 Sep-Oct;27(5):543-7. http://dx.doi.org/10.1590/0103-6440201601014. PMid:27982231.

19. Campos F, Valandro LF, Feitosa SA, Kleverlaan CJ, Feilzer AJ, de Jager N, et al. Adhesive cementation promotes higher fatigue resistance to zirconia crowns. Oper Dent. 2017 Mar/Apr;42(2):215-24. http://dx.doi.org/10.2341/16-002-L. PMid:27892840.

20. Bottino MA, Snellaert A, Bergoli CD, Özcan M, Bottino MC, Valandro LF. Effect of ceramic etching protocols on resin bond strength to a feldspar ceramic. Oper Dent. 2015 Mar-Apr;40(2):E40-6. http://dx.doi.org/10.2341/13-344-L. PMid:25535782.

21. Usumez A, Hamdemirci N, Koroglu BY, Simsek I, Parlar O, Sari T. Bond strength of resin cement to zirconia ceramic with different surface treatments. Lasers Med Sci. 2013 Jan;28(1):259-66. http://dx.doi.org/10.1007/s10103-012-1136-x. PMid:22718473.

22. Wandscher VF, Prochnow C, Rippe MP, Dorneles LS, Callegari GL, Baldissara P, et al. Retentive strength of y-tzp crowns: comparison of different silica coating methods on the intaglio surfaces. Oper Dent. 2017 Sep-Oct;42(5):E121-33. http://dx.doi.org/10.2341/16-090-L. PMid:28829934.

23. Zhao L, Jian YT, Wang XD, Zhao K. Bond strength of primer/cement systems to zirconia subjected to artificial aging. J Prosthet Dent. 2016 Nov;116(5):790-6. http://dx.doi.org/10.1016/j.prosdent.2016.03.020. PMid:27312655.

24. Anami LC, Lima JM, Corazza PH, Yamamoto ET, Bottino MA, Borges AL. Finite element analysis of the influence of geometry and design of zirconia crowns on stress distribution. J Prosthodont. 2015 Feb;24(2):146-51. http://dx.doi.org/10.1111/jopr.12175. PMid:24975118.

\section{CONFLICTS OF INTERESTS}

The authors declare no conflicts of interest.

\section{${ }^{*}$ CORRESPONDING AUTHOR}

Jean Soares Miranda, UNESP - Universidade Estadual Paulista, Instituto de Ciência e Tecnologia, Av. Engenheiro Francisco José Longo, 777, Jardim São Dimas, 12245-000 São José dos Campos - SP, Brasil, e-mail: jeansoares@msn.com 